\title{
Assessing Impacts of a Learning-Cycle-Based Module on Students' Conceptual Sustainability Knowledge using Concept Maps and Surveys \\ Mary Katherine Watson $(\mathrm{PhD})^{1,{ }^{*}}$, Joshua Pelkey ${ }^{2}$, Caroline Noyes $(\mathrm{PhD})^{3}$, Michael Rodgers $(\mathrm{PhD})^{4,5}$
}

* Corresponding author

${ }^{1}$ Civil and Environmental Engineering

The Citadel, The Military College of South Carolina

email: mwatson9@citadel.edu

${ }^{2}$ VMware AirWatch

email: joshpelkey@air-watch.com

${ }^{3}$ Center for the Enhancement of Teaching and Learning

Georgia Institute of Technology

email: caroline.noyes@carnegie.gatech.edu

${ }^{4}$ Civil and Environmental Engineering

Georgia Institute of Technology

email: michael.rodgers@ce.gatech.edu

${ }^{5}$ Georgia Tech Research Institute

\begin{abstract}
As engineers will be the designers of projects that will have lasting economic, environmental, and social impacts, it is important to ensure that students are equipped with the necessary conceptual knowledge to engage in sustainable design. Reforms in engineering education are needed to ensure that sustainability content is included in undergraduate curricula. In addition, previous work has demonstrated that beyond curricular content, innovative pedagogical approaches are also important for enhancing student learning. The goal of this work was to examine the impact of a learning-cycle-based sustainability module on students' conceptual understanding of sustainability. The module was integrated into a senior-level, civil and environmental engineering capstone design course at a large, research-intensive university in the southeastern United States. Concept maps and student self-report surveys were used to compare learning gains for students in the modified design course (intervention cohort) to those in the traditional design course (control cohort). Concept map results indicated that improvements in knowledge depth, breadth, and interconnectedness were significantly greater for the intervention, as compared to the control cohort. Furthermore, while both cohorts initially over-emphasized the environmental dimension of sustainability, only those students in the intervention cohort demonstrated a more balanced understanding of sustainability at the end of the course. Survey results did not show the significant learning gains seen in concept maps, but it is expected that
\end{abstract}


students' survey responses were biased by their negative perceptions of the module itself at the end of the semester. Future module implementations, which can be adapted for a variety of engineering and even non-engineering disciplines, should ensure more complete integration into the target course to improve student perceptions of the learning experience. Overall, this study provides theoretically-grounded, empirically-tested learning materials and assessment methods than can be adapted in other engineering courses.

Keywords: sustainability module, Kolb's learning cycle, concept maps, conceptual knowledge, engineering education 


\section{Nomenclature}

\begin{tabular}{|c|c|}
\hline $\begin{array}{l}\text { Abbreviation } \\
\text { or Symbol }\end{array}$ & Description \\
\hline $\mathrm{NC}$ & $\begin{array}{l}\text { Number of concepts; Concept map component that is an indicator of knowledge } \\
\text { depth }\end{array}$ \\
\hline $\mathrm{HH}$ & Highest hierarchy; Number of concepts in the longest path down hierarchy \\
\hline NCL & $\begin{array}{l}\text { Number of cross-links; Number of connections between concepts from different } \\
\text { concept map hierarchies }\end{array}$ \\
\hline Comp. & $\begin{array}{l}\text { Comprehensiveness; Concept map scoring dimension that considers the variety of } \\
\text { topics (knowledge breadth) and also how extensively topics are covered } \\
\text { (knowledge depth) }\end{array}$ \\
\hline Org. & $\begin{array}{l}\text { Organization; Concept map scoring dimension that considers the concept map } \\
\text { structure, including the links within and between hierarchies (knowledge } \\
\text { connectedness) }\end{array}$ \\
\hline Corr. & $\begin{array}{l}\text { Correctness; Concept map scoring dimension that characterizes the overall } \\
\text { appropriateness of propositions and concept placement }\end{array}$ \\
\hline $\mathrm{CD}_{\mathrm{i}, \mathrm{j}}$ & $\begin{array}{l}\text { Concept distribution for category } i \text { and student } j \text {; Percentage of the number of } \\
\text { concepts in category } i \text { as compared to the total number of concepts in a concept } \\
\text { map }\end{array}$ \\
\hline $\mathrm{NC}_{\mathrm{i}, \mathrm{j}}$ & Number of concepts included in category $i$ for student $j$ 's concept map \\
\hline $\mathrm{NC}_{\mathrm{j}}$ & Number of concepts included in student $j$ 's concept map \\
\hline$\left(\mathrm{L}_{\mathrm{cat}}\right)_{\mathrm{j}}$ & $\begin{array}{l}\text { Relative measure of connections between concepts from different categories for } \\
\text { student } j\end{array}$ \\
\hline $\mathrm{NIL}_{\mathrm{j}}$ & $\begin{array}{l}\text { Number of interlinks, or connections between concepts from different categories, } \\
\text { within student } j \text { 's concept map }\end{array}$ \\
\hline$\left(\mathrm{N}_{\mathrm{cat}}\right)_{\mathrm{j}}$ & number of categories included by student $j$ \\
\hline $\mathrm{CO}_{\mathrm{j}}$ & categorical complexity index for student $j$ \\
\hline$\alpha$ & Krippendorff's alpha; Measure of inter-rater reliability \\
\hline$M$ & Arithmetic mean of data set \\
\hline$p$ & Level of marginal significance within a statistical hypothesis test \\
\hline$n$ & Number of students in sample \\
\hline$F$ & $F$ statistic \\
\hline$\pi_{6-7}$ & Proportion of students providing a response of 6-7 on a seven-point Likert scale \\
\hline$\Delta_{\text {post-pre }}$ & Change in score between the pre- and post- assessment \\
\hline
\end{tabular}




\section{Introduction}

Engineers, as the designers of infrastructure that will have immediate and longtermimpacts on the world, are especially poised to contribute to a sustainable future(Lonngren and Svanström, 2015; Wals et al., 2014). However, for engineers to positively impact sustainable development, efforts are needed to reform both the curricular content of undergraduate curricula, as well as the pedagogical approaches used to encourage student learning.

\subsection{Curricular Content Reform}

A new "focus" is needed for engineering education to ensure that students are not only technically-competent, but are also equipped to tackle problems from a sustainability perspective (Hadgraft and Goricanec, 2007). Currently, engineering education emphasizes overspecialization and procedural problem solving rather than the holistic and systems thinking that is needed to analyze complex problems (Lonngren and Svanström, 2015; Seager et al., 2012). As a result of the lack of breadth in undergraduate curricula, Davidson et al. (2007) cautions that students may be unable to adapt to future conditions where "engineers must be able to design with natural resources that have very different constraints for a wider variety and greater number of end users." While sustainability can be integrated into a variety of courses, within the context of engineering education, many authors have worked to include sustainability in capstone design courses (e.g., Pierrakos et al., 2013; Yuan et al., 2015). The real-world projects tackled in capstone design provide a natural context for students to learn about and apply sustainability principles in conjunction with concepts and skills from other technical courses.

To remediate the shortcomings of current engineering education (and perhaps of higher education more broadly), curricula should guide students in becoming able to consider the economic, environmental, and social aspects of sustainability during analysis and design. Indeed, Lonzano and Peattie (2011) agree that efforts are needed to guide students in developing a balanced view of sustainability, with knowledge of all dimensions. While students may be familiar with environmental protection(Watson et al., 2013b), efforts may be needed to introduce students to qualitative and quantitative methods for considering the under-emphasized social dimension of sustainability(Salzmann et al., 2005). Even still, though economic analysis is a common skill included in many engineering curricula, students may not understand how it relates to sustainability(Barrella and Watson, 2015). As encompassed in the STAUNCH® ${ }^{\circledR}$ rating system, curricula should strive to guide students in developing a balanced perspective of sustainability(Lozano and Peattie, 2011). In addition to emphasis on the sustainability dimensions, however, students need to possess the "cross-cutting" skills, such as holistic and systems thinking, to identify and analyze connections between the sustainability dimensions (Lozano and Peattie, 2011; Watson et al., 2013a). For engineers specifically, the need for 
instruction on sustainable design and sustainability assessments have also been discussed (Sisiopiku et al., 2015).

\subsection{Pedagogical Reform}

In addition to curricular content, the pedagogical approaches that are used to execute a curriculum are also important. While lecture-based instruction dominates in engineering education (Mills and Treagust, 2003; Wankat and Oreovicz, 2015), research has shown that more engaging and student-centered pedagogies more effectively promote student learning(Prince, 2004). Specifically, constructivist, social constructivist, and experiential learning theories can be used to enhance learning.

Constructivist theory proposes that knowledge is constructed by the learner. In contrast to the positivist viewpoint that objective knowledge can simply be transferred from teacher to learner, constructivists postulate that students construct knowledge as they process their own experiences(Bhattacharya and Han, 2001; Prince and Felder, 2006). Social constructivist theory goes further to suggest that learning occurs as students internally construct knowledge through their social interactions within a community (Cobb and Yacke, 1996; Eggen and Kauchak, 2010; Kim, 2001). Consequently, active and collaborative teaching and learning practices, where students take responsibility for their learning processes and strive to learn from peers, are two pedagogies that are rooted in constructivist and social constructivist learning theories (Prince, 2004; Prince and Felder, 2006).

Originally proposed by Kolb and based on constructivist theory, experiential learning theory is a model for adult development which asserts that experiences play a key role in the learning process. Experiential learning theory postulates that learning is "the process whereby knowledge is created through the transformation of experience (Kolb, 1984)." Thus, learning occurs as students process educational experiences and integrate resulting conclusions into their existing knowledge bases. Furthermore, the model proposes that student learning occurs in two stages: grasping experiences and transforming experiences. Students may grasp or perceive experiences through concrete experience (CE) or abstract conceptualization (AC). Concrete experiences may occur by perceiving information by using one's senses, while AC can include perceiving information through concepts or symbols (Harb et al., 1993). Once experiences have been grasped, they are transformed or processed through reflective observation (RO) or active experimentation (AE). Those that reflectively process experiences may do so by contemplating the actions of themselves or others, while active processers may begin to immediately experiment with their new-found conclusions. Depending on a student's learning style, he or she will often use a preferred method for grasping experiences (CE or AC) and transforming experiences (RO or AE) (Kolb, 1984; Kolb et al., 2000).

Based on experiential learning theory, Kolb postulates that complete learning occurs when students engage in all phases of a learning cycle (Figure 2.14). Learning begins when a student engages in a given experience $(\mathrm{CE})$ and continues as he or she reflects on that experience 
(RO). Student reflection leads to development of logical conclusions, to which theoretical or expert ideas can be added (AC). Finally, students apply new concepts and skills are tested (AE) to serve as templates for new experiences (CE) (Kolb, 1984; Kolb et al., 2000). Often referred to as "teaching around the cycle (Prince and Felder, 2006)," Kolb's ELT suggests that an instructor can promote complete learning by designing course materials (Harb et al., 1993) to encourage students to complete all learning cycle phases (Figure 2.14). When teaching around the cycle, students are encouraged to learn as they are taught using their preferred styles. However, teaching students using less-preferred styles may help them to develop new ways of thinking about problems or ideas (Kolb et al., 2000; Prince and Felder, 2006; Svinicki and Dixon, 1987).

Discipline-independent theories and pedagogies can be effective for facilitating effective teaching and learning related to sustainability. Expert perceptions of pedagogies for sustainability education were explored by Segalàs, Mulder, \& Ferrer-Balas(2012) through interviews. Almost all experts (88\%) supported project-based learning as the most advantageous "active" strategy for introducing sustainability to students. Even so, many instructors (71\%) also supported traditional lecturing as being important for providing students with fundamental information before engaging in active learning. Other popular active pedagogies included use of case studies (41\%) and discussions and debates (29\%). Overall, experts emphasized the fact that a "multi-pedagogy" approach is needed to reach a variety of students and promote metacognition. Expert beliefs about sustainable education were confirmed in another work by Segalàs and collaborators (2010), which showed that student learning about sustainability was improved when experiential and active learning pedagogies were used in the classroom. Thus, student learning about sustainability can be encouraged by providing opportunities for collaborative, student-driven experiences.

Despite the advantages of student-centered pedagogies, some research has demonstrated that students are often resistant to new and unfamiliar teaching practices. When comparing student- and instructor-centered pedagogies in an electrical engineering class, Yadav et al. (2011)found that learning gains were highest in problem based learning sessions, despite students' beliefs that traditional lectures were most effective. Promising however, Recabarren et al. (2015) reported that student preference for pedagogies depended to some extent on the practices they had been exposed to in the past. Although students engaged primarily in instructor-centered courses tended to prefer these traditional teaching methods, student preference changed after experiencing student-centered courses (Recabarren et al., 2015). Overall, although student-centered courses have been shown to enhance student learning, students' unfamiliarity with the innovative teaching practices may lead to resistance or distrust.

\subsection{Assessment Tools to Evaluate Curricular Reforms}

Effective methods for assessing student understanding of sustainability concepts are needed to successfully integrate sustainability into current engineering curricula. First, summative assessments of student sustainability knowledge can provide a benchmark to aid in 
curricular evaluation. By identifying areas of student proficiency and deficiency, educators can devise sustainability integration strategies, which may include addition or modification of courses. In addition, curricular interventions can be evaluated using a quasi-experimental design in which student understanding is quantified before and after course addition or improvement. Finally, formative assessment can be conducted throughout the course of sustainability-related and sustainability-focused classes to promote learning by informing students about their progress. Thus, innovative assessment strategies are needed to promote individual student learning, as well as provide insights for course and curricula evaluation. Due to the evolving and subjective nature of sustainability itself (Carew and Mitchel, 2008; Coral, 2009; Martin et al., 2005), however, assessing student sustainability knowledge can be difficult. Two proposed assessment tools in the literature are student self-report surveys and concept maps.

\subsection{Insights from Student Self-Report Surveys}

Student self-report surveys are indirect measures of student sustainability knowledge. Surveys typically ask students to reflect on various aspects of their sustainability knowledge and use a provided scale to report answers. As previously discussed in Watson et al. (2013a), different survey formats and results for various populations abound in the literature. Analyzing survey results broadly, student self-report surveys show that student knowledge may vary widely depending on academic standing (e.g., Bielefeldt, 2011), geographic location(e.g., Barth and Timm, 2011), and gender(e.g., Kagawa, 2007), among other factors. One important finding from student surveys is that students tend to perceive to know more about the environmental, as compared to economic or social, dimensions of sustainability(e.g., Kagawa, 2007; Tuncer, 2008; Watson et al., 2013b). One drawback to using surveys as assessment tools is that students' perceptions of their cognitive understanding are often greater than their actual knowledge (Kleitman and Stankov, 2001; Lundeberg et al., 2000; Yadav et al., 2011).

\subsection{Concept Maps as Innovative Assessment Tools}

Concept maps, which are graphical tools for organizing knowledge, are alternatives to student surveys for knowledge assessments. Construction of a concept map is completed by enclosing concepts related to a central topic in boxes and using connecting lines, as well as linking phrases, to depict relationships between concepts (Novak and Canas, 2006). Use of concept maps is supported by semantic memory theory, which posits that students' knowledge networks are formed by creating directed links between related concepts(Tulving, 1972). Interconnectedness of concepts within the structure is an important network characteristic, since it increases one's ability to access concepts (Turns et al., 2000) and is a key feature that differentiates expert and novice knowledge frameworks (Ruiz-Primo, 2000). Since concept maps mimic the structure of internal semantic networks, student-generated constructs may be used to infer a student's understanding about a given domain (Ruiz-Primo, 2000). Indeed, the 
reliability and validity of concept maps as assessment tools have already been established (McClure et al., 1999; Ruiz-Primo et al., 2001; Ruiz-Primo and Shavelson, 1996). More extensive reviews of concept maps are previously published by Novak, Cañas,Gowin, and collaborators (Canas et al., 2003; Novak and Canas, 2006; Novak and Gowin, 1984).

While useful for a variety of domains, concept maps are especially suited for assessing sustainability knowledge. Concept maps allow students to explicitly reveal knowledge content, while also demonstrating how that content is structured (e.g., Besterfield-Sacre et al., 2004). Sustainability is a rapidly-evolving and complex knowledge domain, in which highly interconnected economic, environmental, social, temporal, and spatial concepts are very important(e.g., Davidson et al., 2007). As a result, concept-map-based assessment tools are ideal for identifying concepts that students associate with sustainability, as well as quantifying the interrelationships between sustainability dimensions.

Indeed, concept maps are beginning to be used for assessment of sustainability knowledge. Using concept maps, Lourdel et al. (2007) found that student knowledge before completing a sustainable development course was focused on economic and environmental dimensions, while student knowledge was "richer and wider" after course completion. Segalàset al. (2008) investigated the effectiveness of six sustainability courses by comparing student concept maps before and after course delivery (Segalàs et al., 2008). Evaluation of concept maps revealed that complexity of concept maps resulting from courses employing constructive and community-based pedagogies was higher than from courses using more traditional instructional strategies (Segalàs et al., 2010). Similarly, Borrego et al. (2009) analyzed concept maps before and after a green engineering course and found that the comprehensiveness, correctness, and organization of student maps increased after course delivery. Use of concept maps as assessment tools are also suggested for characterizing student understanding of social sustainability in a sustainable construction course (Harris, 2000; Kates et al., 2005; NRC, 1999). Thus, concept maps are beginning to be applied as assessment tools for studying student conceptual knowledge, but additional work is needed to evaluate scoring methods.

\subsection{Study Purpose}

The purpose of this study was to quantify the impacts of a learning-cycle-based module, enriched with active and collaborative pedagogies, on students' conceptual understanding of sustainability. The module was integrated into a senior-level, civil and environmental engineering design course at the Georgia Institute of Technology (Georgia Tech) in the southeastern United States. The research objective was to compare changes in sustainability knowledge based on concept map and survey-based assessments between a group of students participating in a traditional engineering design course and one enhanced with the learningcycle-based module. Results will be used to provide insights for future module implementations and sustainability knowledge assessments. 


\section{Learning-Cycle-Based Sustainability Module}

A sustainability module was designed to guide undergraduate civil engineering students in learning about and applying sustainability concepts. The sustainability module is intended for integration into an undergraduate course with a real-world design project. The learning objectives of the module were to: (1) Describe sustainability by using breadth and depth of knowledge related to the economic, environmental, social, and temporal aspects of sustainability, (2) Summarize the interconnected nature of the economic, environmental, social, and temporal aspects of sustainability, (3) Analyze the impacts of a project on the economic, environmental, and social systems, and (4) Apply principles of sustainable engineering during design. Although details of the module are provided in a previous publication(Watson et al., 2012), key highlights are summarized below to provide context for the presented results.

\subsection{Module Components}

The module is composed of five components that include material to promote student understanding of sustainable development and design, as well as assessments to gauge student learning. In Session 1, students create sustainability concept maps and complete a self-reported knowledge surveyto benchmark their sustainability knowledge. During Session 2, students learn about sustainable development broadly before focusing on specific themes, such as environmental, economic, and social sustainability, as well as sustainable design, and sustainability assessment (Table 1). Outside of class, each student becomes an "expert" on sustainable development and one of the five sustainability themes by reading key literature, responding to a reflection prompt, reviewing a comprehensive written tutorial, and preparing a mini-lecture for group members. In class, each student-expert teaches other group members about his or her theme. During session 3, student groups reviewsustainability case studies and answer a series of questions designed to guide them in identifying application of sustainability concepts (discussed in session 2) in real-world projects. During Session 4, students apply their sustainability knowledge by completing a preliminary sustainability analysis of their own semester design project and summarizing results in a short report.Finally, in Session 5, students showcase their sustainability knowledge by again creating sustainability concept maps and completing a self-reported knowledge survey. 
Table1. Topics covered in tutorials on sustainable development and sustainability themes.

\begin{tabular}{ll}
\hline Sustainable Development & Social Sustainability \\
\hline - Tragedy of the Commons & - Socially sustainable communities \\
- Definition of sustainable development & - Methods to promote social sustainability \\
- Triple-Bottom-Line Model & - Stakeholder engagement \\
- Nested Dependencies Model & - Stakeholder mapping \\
\hline Environmental Sustainability & Sustainable Engineering \\
\hline - Fundamentals of ecosystems & - Sustainable design methodologies \\
- Ecosystem goods and services & - Nine Principles of Sustainability \\
- Environmental impact assessments & Engineering \\
- Lifecycle analysis & - Strategic design tools (e.g. Design Abacus) \\
\hline Economic Sustainability & Sustainability Assessment \\
\hline - Economic growth and development & - Origin of sustainability assessments \\
- Neoclassical and ecological economics & - EIA-driven sustainability assessment \\
- Five Capitals Model for economic & - Objectives-led sustainability assessment \\
\hline
\end{tabular}

\subsection{Module Theoretical Basis}

The sustainability module was designed to encourage students to engage in active and collaborative learning as they complete Kolb's learning cycle (Figure 1). The module begins with the concrete experience of students reading primary text related to sustainability. Next, during reflective observation, students respond to and submit reflection prompts. During abstract conceptualization, students review sustainability tutorials to develop and deliver mini-lecturers to their peers. As part of active experimentation, students examine sustainability case studies and apply concepts to their own design projects.

As is suggested by constructivist and social constructivist theory, module activities are intended to be collaborative and student-driven, with the instructor serving only as a facilitator. To encourage student and group autonomy, detailed workbooks were provided to students to guide them through the activities. Workbook contents for Session 2 included required readings, reflection questions, detailed tutorials, and outlines for note-taking during peer lectures, and notes pages for all sustainability themes. Directed case study questions and project descriptions were included for Sessions 3 and 4, respectively. In addition, directions for completing beforeand in-class assignments for each module component were included. Instructional materials are available upon request. 


\begin{tabular}{|c|c|c|}
\hline $\begin{array}{l}\text { During Session 5: } \\
\text { - Begin preliminary sustainability } \\
\text { assessment with group members. } \\
\text { After Session 5: } \\
\text { - Finalize analysis. } \\
\text { - Prepare report. } \\
\text { - Submit to instructor for feedback. }\end{array}$ & Concrete Experience & $\begin{array}{l}\text { Before Session 2: } \\
\text { - Review primary literature for sustainability } \\
\text { overview and expert topic. } \\
\text { - Respond to reflection question for } \\
\text { sustainability overview and for expert topic. } \\
\text { - Submit reflections. }\end{array}$ \\
\hline Active Experimentation & & Reflective Observation \\
\hline $\begin{array}{l}\text { Before Session 4: } \\
\text { - Review two case studies. } \\
\text { - Record questions and comments about } \\
\text { case studies. } \\
\text { During Session 4: } \\
\text { - Discuss case studies with group } \\
\text { members. } \\
\text { - Complete case study assignment } \\
\text { questions with group members. } \\
\text { - Submit case study questions to } \\
\text { instructor (one copv per group). }\end{array}$ & $\begin{array}{c}\text { Abstract } \\
\text { Conceptualization }\end{array}$ & $\begin{array}{l}\text { Before Session 3: } \\
\text { - Review tutorials on sustainability overview } \\
\text { and expert topic. } \\
\text { - Prepare mini-lecture on expert topic using } \\
\text { provided lecture outline. } \\
\text { - Review/skim tutorials on other students' } \\
\text { topics before class. } \\
\text { During Session 3: } \\
\text { - Deliver mini-lecture to group members. } \\
\text { - Record key concepts during other members' } \\
\text { mini-lectures using provided lecture outlines. } \\
\text { - Have lecture outline visually checked by } \\
\text { instructor. }\end{array}$ \\
\hline
\end{tabular}

Figure1. Sequence of class activities based on Kolb's learning cycle.

\section{Study Methods}

\subsection{Study Site}

The impacts of participation in the learning-cycle-based sustainability module on students' conceptual understanding of sustainability were investigated in a civil and environmental engineering capstone design course at Georgia Tech. Enrollment in the capstone design course required senior-standing and completion of all major design courses. While in capstone design, students are mentored by instructors and engineering professionals as they complete a real-world design. Most students' primary exposure to sustainability concepts is during their second academic year when taking a civil engineering systems course which is intended to introduce students to sustainability from a systems perspective (Amekudzi and Meyer, 2004). The impetus of this study was to reinforce concepts learned in the civil engineering systems course, as well as encourage students to apply concepts in a design context. Additional information about the curriculum are available (Watson et al., 2013b).

\subsection{Experimental Design}

A quasi-experimental, untreated cohort control group design (Shadish et al., 2002) was used to investigate the impacts of module completion on student learning in the capstone design course. Since cohorts of students tend to have similar backgrounds and demographics (Fitzpatrick and Kazer, 2011), using an equivalent cohort as a control group is suggested 
tominimize selection biases that can be present in the commonly-used nonequivalent comparison group design (Shadish et al., 2002; Takona, 2002). Students enrolled in thetraditional capstone design course during Fall 2011 were not exposed to the sustainability module (control cohort), while students enrolled in the modified capstone design course during Spring 2012 completed all sessions of the sustainability module (intervention cohort). Other than integration of the sustainability module, the intervention course was identical to the control course, including being led by the same two faculty instructors.

Knowledge assessments were administered at the beginning and end of the semester for both cohorts. Completion of survey and concept map assessments, as well as other module deliverables, accounted for $5 \%$ of the overall course grade. All assessments were completed during class and were graded based on completion. Thus, incentive to demonstrate learning was the same in both the control and intervention cohorts.

A majority of students in the two capstone courses participated in the study. Of the 67 students in the control cohort, 38 completed both pre- and post- concept map assessments, while 47 completed both pre- and post- surveys. Of the 100 students in the intervention cohort, 72 completed both pre- and post- concept map assessments, while 84 completed both pre- and postsurveys. Since over $95 \%$ of students consented to participate in the study, differences in sample sizes were due to normal enrollment fluctuations and not to low consent rates.

\subsection{Assessment of Conceptual Learning}

A section of a previously-developed sustainability knowledge survey was administered as an indirect measure of student knowledge. Specifically, students were prompted to reflect on their knowledge of sustainable development, including environmental, social, and economic aspects using seven-point scales. The survey was administered in paper-form and students were given 30 minutes to answer questions. Additional details on survey, including development, administration, and final questions are available (Watson et al., 2013b).

Concept map assessments were used as a direct measure of student knowledge, as detailed in previous publications (Watson et al., 2014; Watson, 2013). Briefly, students were trained on how to construct concept maps and provided up to three hours to complete their sustainability concept maps, although most students only took approximately 30 minutes.Students used CmapTools(Cañas et al., 2004), a free concept mapping software, to construct and organize their concept maps. After submission, two judges individually examined concept maps using the traditional, holistic, and categorical scoring methods. Judges discussed discrepancies in their scores in order to arrive at a set of consensus scores.

The traditional scoring method (e.g., Besterfield-Sacre et al., 2004; Novak and Gowin, 1984) involves quantifying the number of components in each concept map. The number of concepts (NC) included in the maps are counted to serveas an indicator of knowledge breadth. Next, hierarchies, which are defined by propositions that include the concept map topic, are 
analyzed. Concepts in each hierarchy are counted and the maximum number of concepts in hierarchy (i.e., the highest hierarchy; $\mathrm{HH}$ ) is an indicator of knowledge depth. Finally, the number of cross-links (NCL), which are links between concepts from different hierarchies, are used as a measure of knowledge connectedness. The total traditional score was calculated by awarding 1 point for each concept, 5 points for each level of hierarchy, and 10 points for each cross-link, as adapted from Novak and Gowin(1984) (Table 2).

Instead of analyzing individual components, the concept map as a whole can be evaluated. For instance, Besterfield-Sacre et al. (2004) developed the holistic scoring rubric in which judges use a three-point scale to rate the comprehensiveness, organization, and correctness of concept maps. The rubric was later modified for application to sustainability concept maps (Table3) (Watson et al., 2015). In analyzing comprehensiveness, judges consider the variety of topics (knowledge breadth) and also how extensively topics are covered (knowledge depth). Scoring the organizational dimension requires evaluation of the concept map structure, including the links within and between hierarchies (knowledge connectedness). Unlike the traditional method, the holistic method includes a correctness sub-score, which characterizes the overall appropriateness of propositions and concept placements. Finally, the total concept map score is computed by simply adding the three sub-scores (Table 2).

Table2.Computation of total traditional ${ }^{\mathrm{a}}$ and total holistic ${ }^{\mathrm{b}}$ scores.

\begin{tabular}{|c|c|c|}
\hline Method & Equation & Adapted from \\
\hline Traditional & Total $=(\mathrm{NC}-\mathrm{NCL})^{\mathrm{c}}+(\mathrm{HH}) * 5+(\mathrm{NCL}) * 10$ & (Novak and Gowin, 1984) \\
\hline Holistic & Total $=$ Comp.+ Org. + Corr & (Besterfield-Sacre et al., 2004) \\
\hline
\end{tabular}


1 Table3.Rubric for holistic concept map scoring method [Modified from Besterfield-Sacre et al.(2004)].

\begin{tabular}{|c|c|c|c|}
\hline & Score $=1$ & Score $=2$ & Score $=3$ \\
\hline \multirow[t]{2}{*}{$\begin{array}{l}\text { Comprehen- } \\
\text { siveness }\end{array}$} & $\begin{array}{l}\text { Breadth: Map lacks subject definition. } \\
\text { Demonstrated by inclusion of only one } \\
\text { major dimension. }\end{array}$ & $\begin{array}{l}\text { Breadth: Map has adequate subject definition but, } \\
\text { knowledge is limited to some areas. Demonstrated } \\
\text { by inclusion of at least } 2 \text { major dimensions. }^{\text {a }}\end{array}$ & $\begin{array}{l}\text { Breadth: Map completely defines the subject } \\
\text { area, with content lacking in no more than } \\
\text { one extension area. Demonstrated by } \\
\text { inclusion of at least } 3 \text { major dimensions }{ }^{\mathrm{a}} \text {. }\end{array}$ \\
\hline & $\begin{array}{l}\text { Depth: Knowledge is very simple or } \\
\text { limited and barely covers some } \\
\text { qualities of the subject area. } \\
\text { Demonstrated by sufficient detail } \\
\text { provided for only one major dimension. }\end{array}$ & 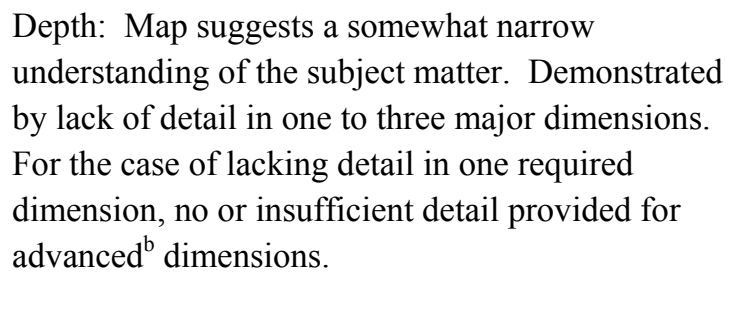 & $\begin{array}{l}\text { Depth: Content demonstrates extensive } \\
\text { understanding of the subject matter. } \\
\text { Demonstrated by sufficient detail in all four } \\
\text { major dimensions, or detail in three major } \\
\text { dimensions and at leastl advanced } \\
\text { dimension. }\end{array}$ \\
\hline \multirow[t]{3}{*}{ Organization } & $\begin{array}{l}\text { Map arranged with concepts mostly } \\
\text { linearly connected. }\end{array}$ & $\begin{array}{l}\text { Map has adequate organization with some } \\
\text { within/between branch connections. }\end{array}$ & $\begin{array}{l}\text { Map is well-organized with concept } \\
\text { integration (requires that no concept appears } \\
\text { twice). Demonstrated by extensive }\end{array}$ \\
\hline & $\begin{array}{l}\text { Few (or no) connections } \\
\text { within/between branches. }\end{array}$ & $\begin{array}{l}\text { Some, but not complete, integration of branches is } \\
\text { apparent. A few feedback loops may exist. }\end{array}$ & connections between/within branches. \\
\hline & Concepts not well integrated. & & $\begin{array}{l}\text { Sophisticated branch structure and } \\
\text { connectivity. Demonstrated by presence of } \\
\text { cross-links and possible feedback loops. }\end{array}$ \\
\hline \multirow[t]{4}{*}{ Correctness } & $\begin{array}{l}\text { Map is naïve and contains inaccurate } \\
\text { knowledge and/or misconceptions }\end{array}$ & Map has few subject matter inaccuracies. & Map integrates concepts properly. \\
\hline & about the subject. & Most links are correct. & $\begin{array}{l}\text { Reflects an accurate understanding of subject } \\
\text { matter. }\end{array}$ \\
\hline & Inappropriate terms used. & & \\
\hline & $\begin{array}{l}\text { Inaccurate understanding of certain } \\
\text { subject matter. }\end{array}$ & & $\begin{array}{l}\text { Few or no inaccuracies and/or } \\
\text { misconceptions }\end{array}$ \\
\hline
\end{tabular}

2 Note. Modified from Besterfield-Sacre et al. (2004). ${ }^{\mathrm{a}}$ Major dimensions: economic, environmental/natural resources, social, and temporal (requires inclusion of

3 present and future considerations) (Segalàs et al., 2008). ${ }^{\mathrm{b}}$ Advanced dimensions: values, spatial imbalances, technology, education, actors and stakeholders

4 (Segalàs et al., 2008). 
An alternative to the traditional and holistic methods, the categorical scoring method was developed specifically for sustainability-related concept maps. To apply the categorical scoring method, judges first categorize each concept in a concept map according to appropriate categories. For the area of sustainability, Segalàs et al. (2008) suggest ten categories based on the earlier categories proposed by Lourdel et al. (2007): environment, natural resources, social impacts, values, temporal aspects, spatial aspects, technology, economy, education, and stakeholders. To further facilitate analysis, the sustainability categories were grouped according to mega-categories. The environmental mega-category was composed of the environment and resource categories. The social mega-category was composed of the social impacts, values, temporal, spatial unbalances, education, and actors/stakeholders categories. The economic mega-category was composed of the economic and technology categories.

Next, judges count the number of inter-links (NIL), or connections between concepts from different categories. Using category assignments and number of inter-links, Segalàs et al. (2008) present a set of cohort-specific metrics, which can be adapted for individual students (Table4). Specifically, the category distribution (CD) can be used to analyze the extent to which a single student associates a specific category with the central topic, while the student-specific complexity index $\left(\mathrm{CO}_{\mathrm{j}}\right)$ can be calculated to characterize the overall coverage of and connectedness between the categories (Table4).

Table4. Metrics associated with the categorical method [Adapted from Segalàset al.(2010)].

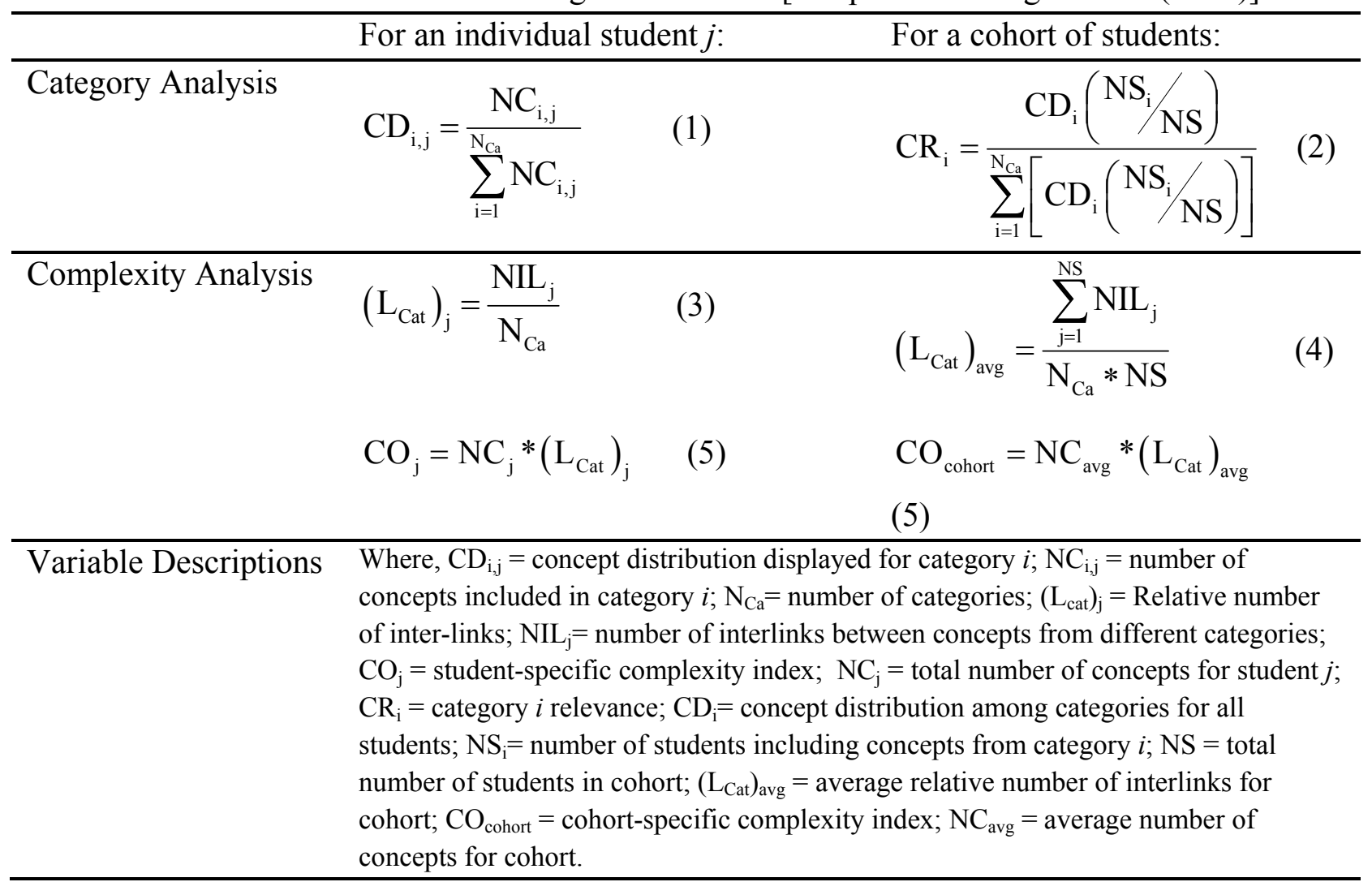




\subsection{Statistical Analyses}

Statistical analyses were completed to analyze concept map and survey data. Inter-rater reliability of judges' individual scores was quantified using Krippendorff's alpha, which can be applied to all levels of measurements and any number of judges (Hayes and Krippendorff, 2007). All Krippendorff's alpha were above 0.67 , which is classified as "acceptable for exploratory research"(Hayes and Krippendorff, 2007; Krippendorff, 2004). Using concept map consensus scores, 2 (control group, intervention group) $\times 2$ (pre-, post-scores) repeated measures ANOVA were employed to determine any trends in data between pre- and post- knowledge assessments, as well as between cohorts. Significant interactions between assessments and cohorts were used to infer impacts caused solely by presence or absence of the module.

Pre- and post- responses to survey items asking students to rate their confidences in their abilities to discuss sustainable development and related dimensions were compared within the control and intervention cohorts using McNemar test. Specifically, the proportion of students indicating that they were very confident in their abilities to discuss different aspects of sustainable development ( $\pi_{6-7}$, as defined as providing a response of 6-7 on a seven-point scale) were compared between pre- and post-assessments. A significance level of 0.05 was used for all hypothesis testing in order to balance the probabilities of Type I and II errors (Rajamanickam, 2001). IBM SPSS Statistics 22 was used for all statistical analyses.

\section{Results}

\subsection{Traditional Concept Map Scoring}

Evaluation of pre- and post-concept maps using the traditional scoring method supports that students participating in the sustainability module experienced positive gains in the breadth of their sustainability knowledge (Table5). Regardless of cohort, students included significantly more concepts in their concept maps at the end of the semester $(M=16.8)$ as compared to the beginning of the semester $(M=13.9)(p \leq 0.001)$. However, the increase in number of concepts was significantly higher for the intervention cohort $\left(\Delta_{\text {post-pre }}=5.1\right)$ as compared to the control cohort $\left(\Delta_{\text {post-pre }}=0.9\right)(p=0.09)$.

In addition to enriching the content of sustainability knowledge, participation in the module also supported development of structurally complex sustainability knowledge networks (Table5). Virtually no changes were observed in the highest hierarchy and number of cross-links between pre- and post-assessments for the control cohort. As a result, improvements in the highest hierarchy of concept maps was statistically higher for the intervention cohort $\left(\Delta_{\text {post-pre }}=\right.$ $+0.3)$, as compared to the control cohort $\left(\Delta_{\text {post-pre }}=-0.3\right)(p=0.009)$. Similarly, improvements in the number of cross-links included in concept maps was substantially higher for the intervention cohort $\left(\Delta_{\text {post-pre }}=+1.5\right)$, as compared to the control cohort $\left(\Delta_{\text {post-pre }}=+1.5\right)(p=$ 
0.042).This indicates that module participants were more able to develop the structural complexity of their sustainability knowledge, both in depth (indicated by highest hierarchy) and connectedness (indicated by number of cross-links), than those enrolled in the unmodified course.

Overall, concept maps constructed by the intervention cohort were of a higher quality than those developed by those in the control cohort (Table5). Total scoresgenerally increased from the beginning $(M=54.6)$ to the end $(M=63.4)$ of the semester, regardless of cohort ( $p=$ 0.035). However, the increase in total traditional scores was significantly higher for students in the intervention cohort $\left(\Delta_{\text {post-pre }}=+20.2\right)$, as compared to those in the control cohort $\left(\Delta_{\text {post-pre }}=\right.$ 0.4) $(p=0.007)$. Overall, students participating in the learning-cycle-based sustainability module were able to enrich both the content and structure of their sustainability knowledge.

Table5.Comparison between pre- and post- concept mapscores ${ }^{\mathrm{a}}$ determined using the traditional scoring approach for control and intervention cohorts [Mean (Standard Deviation)].

\begin{tabular}{|c|c|c|c|c|c|c|c|}
\hline & \multicolumn{2}{|c|}{$\begin{array}{c}\text { Control } \\
\text { Cohort }(n=38)\end{array}$} & \multicolumn{2}{|c|}{$\begin{array}{c}\text { Intervention } \\
\text { Cohort }(n=72) \\
\end{array}$} & \multicolumn{3}{|c|}{$\begin{array}{c}\text { Repeated Measures ANOVA } \\
\qquad F(1,108)\end{array}$} \\
\hline & Pre & Post & Pre & Post & Test & Cohort & $\begin{array}{l}\text { Test } \times \\
\text { Cohort }\end{array}$ \\
\hline $\mathrm{NC}$ & $13.5(6.2)$ & $14.4(8.5)$ & $14.2(6.2)$ & $19.3(10.3)$ & $14.10^{* * *}$ & 3.89 & $7.06^{* *}$ \\
\hline $\mathrm{HH}$ & $3.5(1.6)$ & $3.2(1.4)$ & $3.3(1.2)$ & $3.6(1.3)$ & 0.06 & 0.08 & $7.04 * *$ \\
\hline NCL & $2.7(2.7)$ & $2.5(3.4)$ & $2.6(3.2)$ & $4.1(6.6)$ & 2.44 & 0.88 & $4.22 *$ \\
\hline Total & $55.3(25.9)$ & $52.7(36.0)$ & $53.9(32.3)$ & $74.1(63.1)$ & $4.56^{*}$ & 1.59 & $7.65^{* *}$ \\
\hline
\end{tabular}

${ }^{a} \mathrm{NC}=$ number of concepts, $\mathrm{HH}=$ highest hierarchy, $\mathrm{NCL}=$ number of cross-links, total = total traditional score as defined in Table 2.

${ }^{*} p \leq 0.05 ;{ }^{* *} p \leq 0.01 ; * * * p \leq 0.001$

\subsection{Holistic Concept Map Scoring}

Analysis of pre- and post- concept maps using the holistic scoring method also suggests that participation in the module improved student sustainability knowledge (Table6). While comprehensiveness sub-scores significantly increased between pre- $(M=1.33)$ and post- $(M=$ 1.53) assessments, regardless of cohort, the magnitude of this increase was significantly higher for the intervention cohort $\left(\Delta_{\text {post-pre }}=+0.5\right)$, as compared to the control cohort $\left(\Delta_{\text {post-pre }}=-0.1\right)$ $(p \leq 0.001)$. As an indicator of student ability to adequately define, as well as demonstrate a high level of understanding for, the knowledge domain (Besterfield-Sacre et al., 2004), comprehensiveness sub-scores suggest significant advancements in knowledge breadth and depth for students participating in the intervention.

In addition to comprehensiveness, the organization of student concept maps also improved after module completion (Table6). Organization sub-scores generally increased 
between pre- $(M=1.30)$ and post-assessments $(M=1.55)$, regardless of cohort. However, the magnitude of improvement was significantly higher for students participating in the module $\left(\Delta_{\text {post-pre }}=+0.5\right)$ compared to those in the control cohort $\left(\Delta_{\text {post-pre }}=+0.0\right)(p \leq 0.001)$. Since the organization sub-score captures student ability to properly arrange and connect concepts within concept maps, this sub-score provides insights into the structure of sustainability knowledge.

While participation in the module positively impacted both the comprehensiveness and organization of sustainability knowledge, it had little effect on the correctness of sustainability knowledge (Table6). Specifically, the correctness sub-score did not vary significantly between pre- and post-assessments or between control and intervention cohorts $(p>0.05)$. Thus, student understanding was not naïve or filled with misconceptions.

Like total traditional scores, total holistic scores confirm the increase in overall quality of intervention concept maps(Table6). Total holistic scores were significantly higher for post- $(M=$ $6.0)$ than for pre-assessments $(M=5.6)$, regardless of cohort $(p \leq 0.001)$. In addition, scores were statistically higher for the intervention $(M=6.0)$ than the control cohort $(M=5.6)$, regardless of assessment time $(p=0.016)$. However, the increase in scores between the pre- and postassessment was substantially higher for the intervention $\left(\Delta_{\text {post-pre }}=+0.9\right)$ than the control $\left(\Delta_{\text {post-pre }}\right.$ $=-0.1)$ cohort $(p \leq 0.001)$. Thus, improvements in comprehensiveness and organization of intervention concept maps led to an overall elevation of concept map quality.

Table6. Comparison between pre- and post- concept mapscores ${ }^{\mathrm{a}}$ determined using the holistic scoring approach for control and intervention cohorts [Mean (Standard Deviation)].

\begin{tabular}{lccccccc}
\hline & \multicolumn{2}{c}{ Control } & \multicolumn{2}{c}{ Intervention } & \multicolumn{3}{c}{ Repeated Measures ANOVA } \\
& \multicolumn{2}{c}{ Cohort $(n=38)$} & \multicolumn{2}{c}{ Cohort $(n=72)$} & \multicolumn{3}{c}{$F(1,108)$} \\
\cline { 2 - 8 } & Pre & Post & Pre & Post & Test & Cohort & Test $\times$ Cohort \\
\hline Comp. & $1.4(0.5)$ & $1.3(0.5)$ & $1.3(0.5)$ & $1.8(0.7)$ & $10.58^{* *}$ & 3.60 & $24.86^{* * *}$ \\
Org. & $1.3(0.6)$ & $1.3(0.5)$ & $1.3(0.5)$ & $1.8(0.8)$ & $11.58^{* * *}$ & 2.68 & $11.58^{* * *}$ \\
Corr. & $3.0(0.2)$ & $2.9(0.4)$ & $2.9(0.3)$ & $3.0(0.0)$ & 1.37 & 0.08 & 3.60 \\
Total & $5.7(0.8)$ & $5.6(0.8)$ & $5.6(0.8)$ & $6.5(1.0)$ & $24.44^{* * *}$ & $5.99^{*}$ & $39.34^{* * *}$ \\
\hline
\end{tabular}

${ }^{a}$ Comp.$=$ comprehensiveness, Org. $=$ organization, Corr. $=$ Correctness, Total $=$ total holistic score as defined in Table 2.

${ }^{*} p \leq 0.05 ; * * \leq 0.01 ; * * * \leq 0.001$

\subsection{Categorical Concept Map Scoring}

Using the categorical method, students in the intervention cohort developed a more balanced understanding of sustainability than their peers in the control cohort (Figure2). Initially, both groups of students severely over-emphasized the environmental dimension, with approximately half of all concepts included in concept maps being related to the environment or natural resources. After their capstone design experiences, students in the control cohort still 
created environmentally-focused concept maps. Conversely, concept maps developed by students after participation in the sustainability module included concepts that nearly equally represented the environmental, economic, and social dimensions of sustainability. As a result, integration of the sustainability module into capstone design helps students develop a more holistic perspective of sustainability.

In addition to improvements in the balance of student sustainability knowledge among dimensions, intervention concept maps also showed an improvement in overall complexity. The student-level complexity index $\left(\mathrm{CO}_{j}\right)$ increased between pre- $(M=11.3)$ and post-assessments $(M=21.0)$, regardless of cohort $[F(1,108)=9.48, \mathrm{p}=0.003]$. However, the increase in $\mathrm{CO}_{\mathrm{j}}$ was substantially more for the intervention cohort $\left(\Delta_{\text {post-pre }}=15.9\right)$ than the control cohort $\left(\Delta_{\text {post-pre }}=\right.$ 3.4) $[F(1,108)=4.07 ; p=0.046]$. Thus, students completing the sustainability module showed significant increases in category-based structural complexity $\left(\mathrm{CO}_{j}\right)$, as compared to their counterparts in the control cohort.

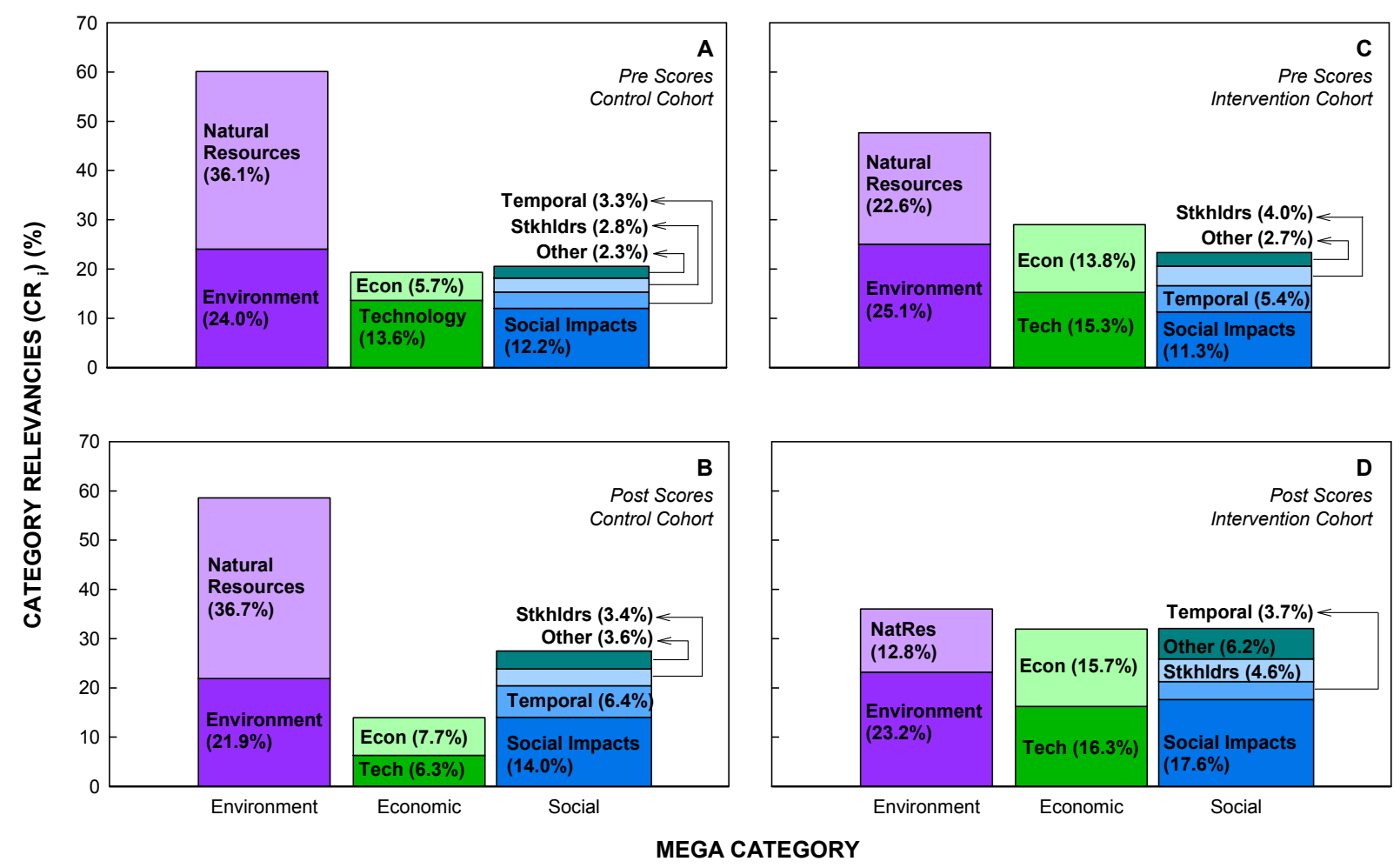

Figure2.Comparison of (A) preliminary and (B) post category relevancies for students enrolled in a traditional capstone design course (control cohort), as well as (C) preliminary and (D) post category relevancies for students enrolled in a capstone course with an integrated sustainability module (intervention cohort). 


\subsection{Student Self-Evaluation of Learning Gains}

Students perceived few changes in their conceptual knowledge of sustainability after completion of the capstone design course, regardless of whether or not they participated in the module (Table 7). Control and intervention students did not indicate increased confidence in their abilities to discuss economic or environmental factors that impact sustainable development, nor in their abilities to discuss connections between different sustainability issues. As expected after participation in the module, student confidence to discuss sustainable development overall did increase significantly within the intervention cohort $(p=0.019)$. The improvement in overall sustainability knowledge without corresponding improvements in knowledge of sustainability dimensions may suggest a lack of sensitivity in using self-report surveys.

However, control students did report a significant increase in their abilities to discuss social factors that affect sustainable development $(p=0.011)$, while intervention studentsdid not. Although intervention students were not more confident after participation in the module, they were at least as confident as the control students at the end of the semester ( $\pi_{6-7}$ approximately $50 \%$ ). It is likely then that the higher perceived knowledge of social sustainability at the beginning of the semester for the intervention cohort $\left(\pi_{6-7}=39.3 \%\right)$ as compared to the control cohort $\left(\pi_{6-7}=23.4 \%\right)$, explains the lack of overall improvement for the intervention cohort. The higher perceived confidence at the beginning of the semester for the intervention cohort could be due to normal variations in student prior knowledge. Alternatively, the intervention cohort may have had a tendency to over-report their knowledge, as has been cautioned by other authors (Kleitman and Stankov, 2001; Lundeberg et al., 2000; Yadav et al., 2011),

\subsection{Student Evaluation of the Module}

To provide guidance on improving future module implementations, students in the intervention cohort were asked to critique the module. Selected student comments which are representative of strengths and weaknesses reflected in all responses are included in Table 9. After Session 2, students indicated that although the activity ran relatively smoothly, more than the allotted time ( $3 \mathrm{hrs}$ ) would have been desirable for each group to complete student sustainability lectures on the five sustainability themes. During student talks, group members were required to record key concepts using instructor-provided outlines. While some students found it helpful to use the outlines as a guide, many felt they constricted the group discussions. Student feedback after analyzing the case study during Session 3 was overwhelmingly positive. Many students indicated that examining a case study (on the Beddington Zero Energy Development, BedZED) dedicated to sustainability was helpful for extracting ideas that could be applied in their own projects. A limited number of students requested a case study that more closely aligned with their projects. While students provided constructive feedback, they suggested that the module activities ran fairly smoothly. 
Despite positive feedback throughout the semester, feedback was more critical at the end of the semester (Table $8-9$ ). Only $29.5 \%$ of students "strongly agreed" that the module helped them to learn about sustainability concepts. After examining open-ended student feedback, it was found that students would have preferred to either (1) focus only on their capstone design projects or (2) have module activities completed at the beginning of the semester or in a different course. 
Table7.Comparison between student-provided rankings to complete several tasks related to sustainable development (SD) before and after completion of a traditional capstone design course (control cohort) and a capstone course with an integrated sustainability module (intervention cohort).

Survey Prompt: The statements below are related to sustainable development. Indicate how confident you are in your ability to discuss:

The concept of sustainable development (SD).

Connections between poverty, population, consumption, and env degradation. Economic factors that affect SD.

Environmental factors that affect SD.

Social factors that affect SD.

${ }^{*} p \leq 0.05 ;{ }^{* *} p \leq 0.01$

\begin{tabular}{|ccc|ccc}
\multicolumn{2}{|c|}{$\begin{array}{c}\text { Control Cohort } \\
(n=47, d f=1) \\
{\left[\pi_{6-7}\right](\%)}\end{array}$} & \multicolumn{3}{c}{$\begin{array}{c}\text { Intervention Cohort } \\
(n=84, d f=1) \\
{\left[\pi_{6-7}\right](\%)}\end{array}$} \\
\hline Pre & Post & $\chi^{2}$ & Pre & Post & $\chi^{2}$ \\
\hline 48.9 & 61.7 & 2.00 & 45.2 & 61.6 & $5.53^{*}$ \\
34.0 & 29.8 & 0.20 & 35.7 & 44.2 & 1.24 \\
29.8 & 36.2 & 0.60 & 34.5 & 38.4 & 0.40 \\
27.7 & 42.6 & 3.77 & 36.9 & 44.2 & 0.86 \\
23.4 & 51.1 & $7.35^{* *}$ & 39.3 & 52.3 & 3.06 \\
\hline
\end{tabular}

Table8.Quantitative student feedback provided after completion of the sustainability module.

Survey prompt: Reflect on the sustainability module you completed this semester during capstone Intervention Cohort design. Indicate the extent to which you agree or disagree with the following statements. $(n=88)\left[\pi_{6-7}\right]$

Participating in the sustainability module helped me learn about sustainability concepts. 29.5 Participating in the sustainability module helped me learn about sustainable design. 
Table9. Qualitative student feedback provided during and after the sustainability module.

Session 2 Reflections

- "[Session 1] went well. Our group shared lots of knowledge of each topic."

- "[Completing lecture outlines] was a good way for us to better understand our teammates' topics."

- "Session 1 did go smoothly. However, the discussion was a bit too forced with the rigid structure of the worksheets."

Session 3 Reflections

- "Session 2 went very smoothly. It helped us all get on the same page and get our project going in a more sustainable direction."

- "Session 2 went really well. We discussed the BedZED project (disadvantages/advantages). With understanding how sustainable practices were implemented into their project, we could take away positive ideas/initiatives for our own capstone project."

- "Session 2 went well. It was interesting to learn about the BedZED project."

Post-Module Reflections

- "Have all the assignments due during the first part of the semester because people might get busier during the second part of the semester. Also, people might want to integrate the knowledge they gained during the module in their projects at an earlier stage"

- 'I'm not really sure a module in the capstone design course is the best format...It seems everyone in the course is focused on their project and not on class activities in the module."

- "Perhaps [the module] would be best implemented before taking senior design."

\section{Discussion}

\subsection{Comparing Concept Maps Between Cohorts}

The learning-cycle-based sustainability module likely had positive influences on student conceptual sustainability knowledge. According to analysis of student-generated concept maps, the content and complexity of students' sustainability knowledge networks were shown to improve significantly more between pre- and post-assessments for the intervention cohort than for the control cohort, regardless of the scoring method used to evaluate concept maps (Figure 3). Importantly, the structural complexity (measured by the highest hierarchy, number of crosslinks, organization sub-score, and complexity index) increased statistically more for intervention students than for control students (Tables 5-6, Figure 2), which is a sign of knowledge integration rather than rote learning, according to Besterfield-Sacre et al. (2004). Knowledge integration, in turn, is a key feature of expert semantic networks that improves the ability to access and utilize information (Turns et al., 2000). Finally, while students' prior knowledge 
about sustainability was environmentally focused, as has been demonstrated in other studies (e.g., Barth and Timm, 2011; e.g., Kagawa, 2007; Tuncer, 2008; Watson et al., 2013b), participation in the module facilitated development of a more balanced understanding among the three sustainability dimensions (Figure 2). Indeed, instructional materials that guide students in developing a balanced view of sustainability can positively impact the quality of an undergraduate curriculum (Lozano and Peattie, 2011). Thus, results of the three concept map scoring methods support that participation in the brief sustainability module promoted student development of expert-like sustainability knowledge. 

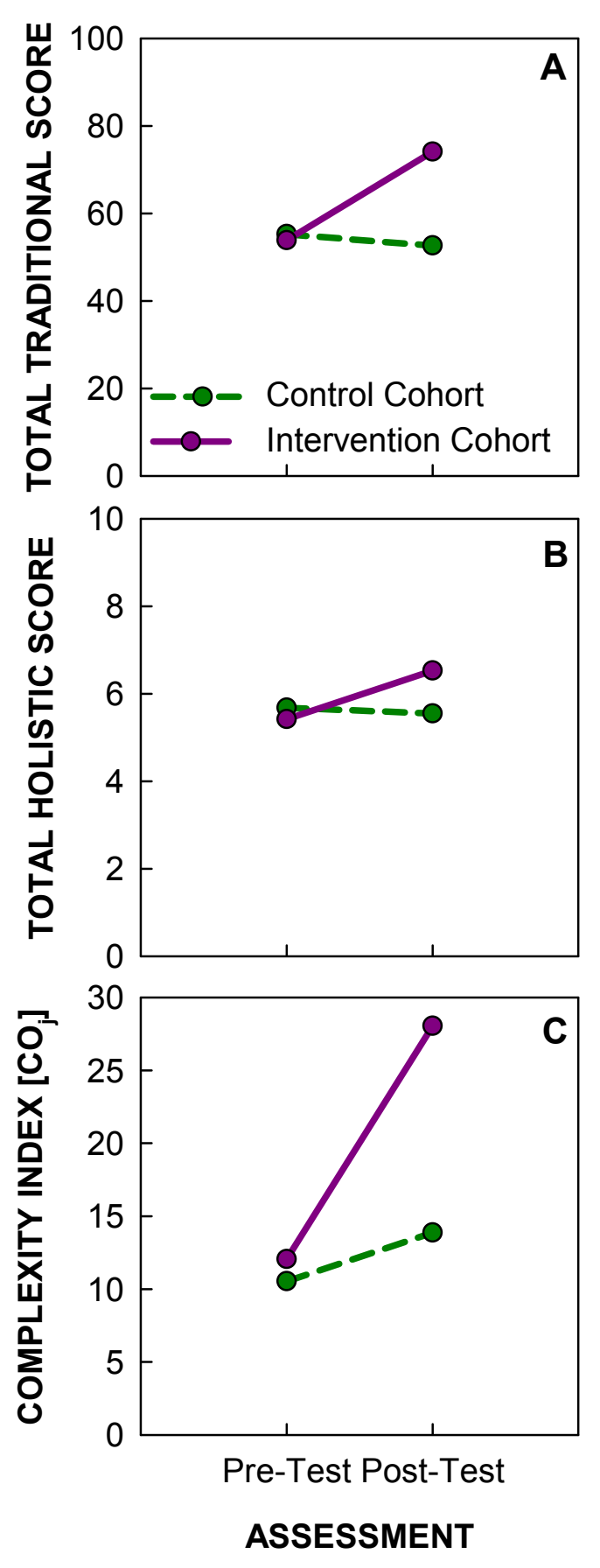

Figure 3.Summary of pre- and post- concept map scores from control and intervention cohorts determined using (A) traditional, (B) holistic, and (C) categorical scoring methods. 


\subsection{Comparison to Other Sustainability-Focused Courses}

Total holistic scores were slightly higher than reported for a similar study of a green engineering course. Borrego et al.(2009) used the holistic approach to score 10 sustainabilityrelated concept maps before and after a two-semester, inter-disciplinary green engineering course and found mean consensus scores to increase from 3.8 to 5.1 on a nine-point scale. In the current study, total holistic scores for the intervention cohort increased from 5.6 to 6.5 after completion of capstone design and the module. It is possible that the starting total scores, and consequently subsequent gains, were higher in the current study due to student completion of a sustainabilityrelated course (Amekudzi and Meyer, 2004)prior to enrollment in capstone design. In addition, some variability in scores may exist since the same set of judges was not used in both studies. Nevertheless, gains in sustainability knowledge, as gauged by the holistic approach, are broadly comparable to other studies.

Cohort-level categorical metrics (Table 4) were also used to benchmark student performance in the sustainability module relative to that of students completing sustainabilityfocused courses administered in the United Kingdom. In the work of Segalàs et al.(2010), students participating in pedagogically-innovative courses demonstrated $\mathrm{CO}_{\text {cohort }}$ gains ranging from zero to 22.2 (average gain $=8.1$ ). In comparison, students participating in the current sustainability module demonstrated a $\mathrm{CO}_{\text {cohort }}$ gain of 12.4, which is well above the mean for traditional courses, but approximately half the gain of the most successful innovative course. Nevertheless, the fairly short sustainability module encouraged gains in student learning on par with other entire sustainability-focused courses incorporating active pedagogies, which supports the ultimate conclusion of Segalàs et al.(2010)that student sustainability learning is best facilitated through employment of community- and constructivist-based approaches.

\subsection{Comparing Learning Gains as Indicated by Concept Maps and Student Surveys}

Although concept map scores suggest an overall improvement in students' conceptual understanding of sustainability, students did not perceive that the module increased their learning. Although intervention students indicated an increase in their ability to discuss sustainable development in general, they did not feel more confident in their abilities to discuss more specific aspects of sustainability at the end of the course.Because concept maps are a valid and reliable direct measure of student knowledge (McClure et al., 1999; Ruiz-Primo et al., 2001; Ruiz-Primo and Shavelson, 1996), it is likely that student sustainability knowledge did in fact improve through participation in the module.

Perhaps then, student dissatisfaction with the sustainability module may be responsible for incongruent survey scores. Given that student resistance tonew and unfamiliar teaching practices has been reported (e.g., Recabarren et al., 2015; Yadav et al., 2011), one source of dissatisfaction may have been resistance to the active learning pedagogies used in the module. As most 
students were familiar with instructor-centered teaching practices in engineering education(Mills and Treagust, 2003; Wankat and Oreovicz, 2015), learning in a student-driven and collaborative environment may have been uncomfortable.

Second, the module may have been viewed as separate from the capstone design course. In fact, many students at the end of the semester commented that they would have preferred to only work on their design projects, rather than completing the module. On average, students spent approximately eight hours of class time and no more than three hours of time outside of class on the sustainability module. For comparison, most students likely spent well over 100 hours (mostly outside of class) on their capstone design project. Overall, the sustainability module required very little commitment from students outside of class and did not reasonably detract from their capstone design efforts. Clearly, some students did not make the connection that the module was intended to help them with their projects by thinking about impacts from a more holistic perspective. Future implementations need to ensure that module is more completely embedded into the course so that students do not view it as extra work.

Finally, the final survey was given only a few days before final projects were due when students were especially stressed. Consequently, student frustrations at the end of the semester could have resulted in biased survey responses. Nevertheless, the results of this study support the use of direct measures of student knowledge (e.g., concept maps), since indirect measures such as surveys may be susceptible to student biases.

\subsection{Implications for Future Module Implementations in Engineering and Beyond}

The primary suggestion for future module implementations is to ensure more complete integration into the undergraduate design course. In the current study, all module activities were presented by the lead author and not by the course instructor, which may have caused some students to view material as not as important as their design projects. In future implementations, the course instructor should be involved in module dissemination to encourage that students prioritize and value the activities. To ensure that students completed module activities, submission of deliverables counted as the students' participation grade ( $5 \%$ of course grade), although components of the design project counted for the remainder of the course grade. In the future, in addition to receiving credit for completing assignments, final products should be judged on the extent to which sustainability is incorporated into the design process, as has been suggested by other authors (Yuan et al., 2015). Overall, it is important to ensure that the module is truly integrated into the course so that students do not view it is an unimportant add-on.

The second consideration for future implementation in engineering courses is the academic level of the design course that is targeted for reform. In the current study, as was done by previous authors (e.g., Pierrakos et al., 2013; Yuan et al., 2015), capstone design was selected as the target course because the design project represented a significant context for students to learn about and practicably apply sustainability knowledge in conjunction with concepts and 
skills from previous technical courses. However, some students indicated that the cognitive load of learning new material and completing their design projects was too challenging. Even still, students may not be open to learning about a new design paradigm at the end of their academic career. Consequently, the module may have more impact (at least from the students' perspectives) in an earlier course.

Finally, while the module was developed for implementation in civil and environmental engineering curricula, it could be modified for application in other engineering or nonengineering curricula. Within an engineering curriculum, the instructor would need to select a different, discipline-specific case study, since the one included in the module is specific for building infrastructure. Within a non-engineering curriculum, the module could be used to facilitate sustainability learning in the context of a course project, even if not a design project. During the peer lecture activity (session 2), only the economic, environmental, and social sustainability themes would useful. The instructor could add new relevant themes or use only the three provided. Nevertheless, the presented learning-cycle-based module could be truncated or revised for integration into other engineering or non-engineering courses.

\section{Limitations}

Several limitations of the methods of this study are acknowledged. Related to the sustainability module itself, some may find the content of the module to be incomplete. Unlike traditional engineering subjects (i.e. statics, dynamics, etc.), however, there is no accepted body of sustainability knowledge for undergraduate engineering students. To develop the module, an extensive literature review on sustainability and sustainable design was conducted(Watson, 2013), including examination of existing sustainability courses (Allen et al., 2008), to ensure appropriateness of module content. In addition, the module was reviewed by a panel of faculty and graduate students from a variety of disciplines to ensure content validity. Even further, employment of learning-cycle- and inquiry-based teaching and learning approaches were intended to help students refine their own learning processes, in addition to improving their sustainability knowledge. Consequently, the module may help students develop the skills needed to acquire knowledge beyond what is included in the module itself.

Additional limitations are noted for the assessment tools used to measure student sustainability knowledge. First, student-provided confidence scores are indirect measures of knowledge and may be over-reported (e.g., Yadav et al., 2011) or biased by student perceptions of the learning environment (e.g., Recabarren et al., 2015). To overcome the shortcomings of surveys, concept maps were used as additional, direct measure of student knowledge. Concept maps, however, may raise validity and reliability concerns. Related to validity, if students are not motivated to construct concept maps, then scores may not be indicative of actual sustainability knowledge. To encourage students to construct quality concept maps, the constructs were graded (at least for completion) and students were provided time in class to complete them. Related to reliability, concept scores may be somewhat subjective since they are 
ultimately based on the perceptions of judges. Threats on the reliability of concept map scores were minimized by using two judges that scored concept maps only after engaging in a process to calibrate their scoring criteria, as documented in Watson et al. (2015). Even for the most subjective holistic scoring approach, Krippendorff's alpha was within the range deemed acceptable for exploratory research. Thus, study methods were designed to promote validity and reliability of concept map scores.

\section{Conclusions}

A study was conducted to analyze the impacts of a learning-cycle-based module on students' conceptual understanding of sustainability. The module was integrated into a seniorlevel civil and environmental engineering capstone design course at Georgia Tech in the southeastern United States. Learning gains for students participating in the modified course (intervention cohort) were compared to those participating in the traditional capstone course (control cohort) using concept maps and student self-report surveys.

Several conclusions were made based on the results. First, students in the intervention cohort demonstrated greater improvements in knowledge breadth, depth, and connectedness, as compared to the control cohort. Second, although students in both cohorts initially overemphasized the environmental dimension of sustainability, only those in the intervention cohort demonstrated a more balanced perspective between economic, environmental, and social dimensions at the end of the semester. Finally, while student surveys did not show the same improvements in knowledge captured in concept maps, differences are attributed to resistance to active learning and/or incomplete integration of the module into the capstone design course.

This study provides several insights for other educators. First, instructional materials examined in this study can be directly integrated into civil and environmental engineering courses, or modifications can be made to make the module appropriate for other engineering disciplines and perhaps even non-engineering fields. While direct measures (i.e., concept maps) indicated that the module did have a positive impact on student knowledge, several improvements are suggested for future implementations. Most importantly, efforts should be made to ensure that students perceive the module to be an integral part of the course and not just an add-on. Suggestions for accomplishing this include having the instructor be involved with module dissemination and have sustainability considerations be part of the final project grading.

Additional implications are provided for educational researchers seeking to develop and assess materials and pedagogies to improve sustainability education. First, the need for multiple assessment methods was demonstrated in this study. Although surveys are a simple and popular way to assess student knowledge, they have several limitations (i.e., susceptibility to under- or over-reporting knowledge). For instance, if only surveys were used to examine the sustainability module, then it may have been concluded that the module was ineffective. Second, the use of concept maps as a direct measure of student knowledge proved to be effective. In fact, three 
different scoring methods were presented and demonstrated in this study. Future researchers can use any or all of these methods to capture student sustainability knowledge.

Overall, the learning-cycle-based sustainability module is one tool for updating both the content and pedagogy of engineering education to train engineers to consider sustainability during the design of the world's products, processes, and infrastructure.Educators can adapt these educational materials for their own classes, while other researchers may find the assessment tools presented in this study valuable for their own endeavors.

\section{Acknowledgement}

Financial support was provided through a National Science Foundation Graduate Research Fellowship awarded to M. K. Watson (DGE-0946809).

\section{References}

Allen, D., Allenby, B., Bridges, M., Crittenden, J., Davidson, C., Hendrickson, C., Matthews, S., Murphy, C., Pijawka, D., 2008. Benchmarking Sustainable Engineering Education: Final Report. Environmental Protection Agency, Washington, DC.

Amekudzi, A., Meyer, M., 2004. The Civil Engineering Systems Course at Georgia Institute of Technology, Engineering Systems Symposium. Massechusettes Institute of Technology, Cambridge, MA.

Barrella, E., Watson, M.K., 2015. Comparing the outcomes of horizontal and vertical integration of sustainability content into engineering curricula using concept maps.

Barth, M., Timm, J.M., 2011. Higher education for sustainable development: Students' perspectives on an innovative approach to educational change. Journal of Social Sciences 7, 13-23.

Besterfield-Sacre, M., Gerchak, J., Lyons, M.R., Shuman, L.J., Wolfe, H., 2004. Scoring concept maps: An integrated rubric for assessing engineering education. Journal of Engineering Education 93, 105-115.

Bhattacharya, K., Han, S., 2001. Piaget and cognitive development, in: Orey, M. (Ed.), Emerging perspectives on learning, teaching, and technology. University of Georgia, Athens, GA.

Bielefeldt, A.R., 2011. Incorporating a sustainability module into first-year courses for civil and environmental engineering students. Journal of Professional Issues in Engineering Education and Practice 137, 78-85.

Borrego, M., Newswander, C.B., McNair, L.D., McGinnis, S., Paretti, M.C., 2009. Using concept maps to assess interdisciplinary integration of green engineering knowledge. Advances in Engineering Education 1, 1-26.

Canas, A.J., Coffey, J.W., Carnot, M.J., Feltovich, P., Hoffman, R.R., Feltovich, J., Novak, J.D., 2003. A Summary of Literature Pertaining to the Use of Concept Mapping Techniques and Technologies for Education and Performance Support The Institute for Human and Machine Cognition, Pensacola, FL.

Cañas, A.J., Hill, G., Carff, R., Suri, N., Lott, J., Gomez, G., Eskridge, T.C., Arroyo, R.C., 2004. CmapTools: A knowledge modeling and sharing environment, in: Cañas, A.J., Novak, J.D., Gonzalez, F.M. (Eds.), Second International Conference on Concept Mapping, Concept Maps: Theory, Methodology, and Technology ed, Pamplona, Spain. 
Carew, A.L., Mitchel, C.A., 2008. Teaching sustainability as a contested concept: Captializing on variation in engineering educators' conceptions of environmental, social, and economic sustainability. Journal of Cleaner Production 16, 105-115.

Cobb, P., Yacke, E., 1996. Constructivist, emergent, and socialcultural perspectives in the context of developmental research. Educational Psychologist 31, 175-190.

Coral, J.S., 2009. Dissertation: Engineering Education for a Sustainable Future. Universitat Politecnica de Catalunya, Barcelona, Spain.

Davidson, C.I., Matthews, H.S., Hendrickson, C.T., Bridges, M.W., Allenby, B.R., Crittenden, J.C., Chen, Y., Williams, E., Allen, D.T., Murphy, C.F., Austin, S., 2007. Viewpoint: Adding sustainability to the engineer's toolbox: A challenge for engineering educators. Environmental Science \& Technology 41, 4847-4849.

Eggen, P., Kauchak, D., 2010. Educational Psycology: Windows on Classrooms, 8th ed. Pearson, Upper Saddle River, NJ.

Fitzpatrick, J.J., Kazer, M.W., 2011. Encyclopedia of Nursing Research. Springer Publishing Company, New York, NY.

Hadgraft, R., Goricanec, J., 2007. Engineering sustainability, Proceedings of the 2007 ASEE Annual Conference.

Harb, J.N., Durrant, S.O., Terry, R.E., 1993. Use of the Kolb learning cycle and the 4MAT system in engineering education. Journal of Engineering Education 82, 70-77.

Harris, J.M., 2000. Basic Principles of Sustainable Development. Tufts University: Global Development and Environment Institute, Medford, MA.

Hayes, A.F., Krippendorff, K., 2007. Answering the call for a standard reliability measure for coding data. Communication methods and measures 1, 77-89.

Kagawa, F., 2007. Dissonance in students' perceptions of sustainable development and sustainability: Implications for curriculum change. International Journal of Sustainability in Higher Education 9, 317-338.

Kates, R.W., Parris, T.M., Leiserowitz, A.A., 2005. What Is Sustainable Development?, Environment. Taylor and Francis Group, Philadelphia, PA.

Kim, B., 2001. Social Constructivism. University of Georgia, Athens, GA.

Kleitman, S., Stankov, L., 2001. Ecological and person-oriented aspects of metacognitive processes in test-taking. Journal of Applied Cognitive Psychology 15, 321-341.

Kolb, D.A., 1984. Experiential Learning: Experience As the Source of Learning and Development. Prentice-Hall, Englewood Cliffs, NJ.

Kolb, D.A., Boyatzis, R.E., Mainemelis, C., 2000. Experiential Learning Theory: Previous Research and New Directions. Lawrence Erlbaum Associates, Inc., Mahwah, NJ.

Krippendorff, K., 2004. Content Analysis: An Introduction to its Methodology, 2nd ed. Sage Publications Inc., Thousand Oaks, CA.

Lonngren, J., Svanström, M., 2015. Assessing "wicked sustainability problem" - Literacy in Engineering Education, American Society for Engineering Education Annual Conference \& Exposition, Seattle, WA.

Lourdel, N., Gondran, N., Laforest, V., Debray, B., Brodhag, C., 2007. Sustainable development cognitive map: a new method of evaluating student understanding. International Journal of Sustainability in Higher Education 8, 170-182.

Lozano, R., Peattie, K., 2011. Assessing Cardiff University's curricula contribution to sustainable development using the STAUNCH (RTM) system. Journal of Education for Sustainable Development 5, 115-128.

Lundeberg, M.A., Fox, P.W., Brown, A.C., Elbedour, S., 2000. Cultural influences on confidence: Country and gender. Journal of Educational Psychology 92, 152-159.

Martin, S., Brannigan, J., Hall, A., 2005. Sustainability systems thinking and professional practice. Journal of Geography in Higher Education 29, 78-89.

McClure, J., Sonak, B., Suen, H.K., 1999. Concept map assessment of classroom learning: reliability, 
validity, and logistical practicality. Journal of Research in Science Teaching 36, 475-492.

Mills, J.E., Treagust, D.F., 2003. Engineering education - Is problem-based or project-based learning the answer? Australasian Jornal of Engineering Education on-line publication, 2-17.

Novak, J.D., Canas, A.J., 2006. The Theory Underlying Concept Maps and How to Construct Them. Institute for Human and Machine Cognition, Pensacola, FL.

Novak, J.D., Gowin, D.B., 1984. Learning How to Learn. Cambridge University Press., New York, NY.

NRC, 1999. Our Common Journey: A Transition Toward Sustainability. National Academic Press.

Pierrakos, O., Barrella, E.M., Nagel, R.L., Nagel, J.K., Henriques, J.J., Imholte, D.D., 2013. An innovative two-year engineering design capstone experience at James Madison University, American Society for Engineering Education Annual Conference \& Exposition, Atlanta, GA.

Prince, M., 2004. Does Active Learning Work? A Review of the Research. Journal of Engineering Education 93, 223-231.

Prince, M.J., Felder, R.M., 2006. Inductive Teaching and Learning Methods: Definitions, Comparisons, and Research Bases. Journal of Engineering Education 95, 123-138.

Rajamanickam, M., 2001. Statistical Methods In Psychological And Educational Research. Concept Publishing Company.

Recabarren, M., Alvarez, C., Diaz, M.I., 2015. Modifying the student's resistance towards active learning with more active-learning.

Ruiz-Primo, A., 2000. On the use of concept maps as an assessment tool in science: What we have learned so far Revista Electrónica de Investigación Educativa 2, 29-53.

Ruiz-Primo, A., Shavelson, R.J., Li, M., Schultz, S.E., 2001. On the validity of cognitive interpretations of scores from alternative concept-mapping techniques. Educational Assessment 7, 99-141.

Ruiz-Primo, M.A., Shavelson, R.J., 1996. Problems and issues in the use of concept maps in science assessment. Journal of Research in Science Teaching 33, 569-600.

Salzmann, O., Ionescu-Somers, A., Steger, U., 2005. The business case for corporate sustainability: Literature review and research options. European Management Journal 23, 27-36.

Seager, T., Selinger, E., Wiek, A., 2012. Sustainable engineering science for resolving wicked problems. Journal of agricultural and environmental ethics 25, 467-484.

Segalàs, J., Ferrer-Balas, D., Mulder, K.F., 2008. Conceptual maps: Measuring learning processes of engineering students concerning sustainable development. European Journal of Engineering Education 33, 297 - 306.

Segalàs, J., Ferrer-Balas, D., Mulder, K.F., 2010. What do engineering students learn in sustainability courses? The effect of the pedagogical approach. Journal of Cleaner Production 18, 275-284.

Segalàs, J., Mulder, K.F., Ferrer-Balas, D., 2012. What do EESD "experts" think sustainability is? Which pedagogy is suitable to learn it?: Results from interviews and Cmaps analysis gathered at EESD 2008. International Journal of Sustainability in Higher Education 13, 293-204.

Shadish, W.R., Cook, T.D., Campbell, D.T., 2002. Experimental and Quasi-Experimental Designs for Genearlized Causal Inference. Houghton Mifflin Company, Boston, MA.

Sisiopiku, V., Peters, R.W., Ramadan, O.E., 2015. Introducing Sustainability into the Civil Engineering Curriculum, American Society for Engineering Education Annual Conference \& Exposition, Seattle, WA.

Svinicki, M.D., Dixon, N.M., 1987. The Kolb model modified for classroom activities. College Teaching 35, 141-146.

Takona, J.P., 2002. Educational Research: Principles and Practice. iUniverse, Inc., Lincoln, NE.

Tulving, E., 1972. Episodic and Semantic Memory, in: Tulving, E., Donaldson, W. (Eds.), Organization of Memory. Academic Press, Oxford, England.

Tuncer, G., 2008. University students' perception on sustainable development: A case study from Turkey. International Research in Geographical and Environmental Education 17, 212-226.

Turns, J., Atman, C., Adams, R., 2000. Concept maps for engineering education: A cognitively motivated tool supporting varied assessment functions. IEEE Transactions on Education 43.

Wals, A.E.J., Brody, M., Dillon, J., Stevenson, R.B., 2014. Convergence Between Science and 
Environmental Education. Science 344, 583-584.

Wankat, P.C., Oreovicz, F.S., 2015. Teaching engineering. Purdue University Press.

Watson, M., Pelkey, J., Noyes, C., Rodgers, M., 2014. Use of Concept Maps to Assess Student Sustainability Knowledge, American Society for Engineering Education Annual Conference and Exposition, Indianapolis, IN.

Watson, M.K., 2013. Assessment and improvement of sustainability education in civil and environmental engineering.

Watson, M.K., Lozano, R., Noyes, C., Rodgers, M., 2013a. Assessing curricula contribution to sustainability more holistically: Experiences from the integration of curricula assessment and students' perceptions at the Georgia Institute of Technology. Journal of Cleaner Production 61, 106-116.

Watson, M.K., Noyes, C., Rodgers, M., 2012. Development of a Structured-Inquiry Module for Teaching Sustainability 'Around the Cycle'. framework 4, 7.

Watson, M.K., Noyes, C., Rodgers, M.O., 2013b. Student perceptions of sustainability education in civil and environmental engineering at the Georgia Institute of Technology. Journal of Professional Issues in Engineering Education \& Practice doi: 10.1061/(ASCE)EI.1943-5541.0000156.

Watson, M.K., Pelkey, J.G., Noyes, C., Rodgers, M.O., 2015. Assessing conceptual knowledge using several concept map scoring methods. Journal of Engineering Education.

Yadav, A., Subedi, D., Lundberg, M.A., Bunting, C., 2011. Problem-based learning: Influence on students' learning in an electrical engineering course. Journal of Engineering Education 100.

Yuan, D., Fraser, J.M., Paudel, A.M., 2015. Incorporating sustainable engineering design principles into senior design proposals, American Society for Engineering Education Annual Conference \& Exposition, Seattle, WA. 